\author{
Соломонов Владимир Александрович
}

\title{
ВОСПРИЯТИЕ СОБСТВЕННОГО БЛАГОПОЛУЧИЯ В ИНОКУЛЬТУРНОЙ СРЕДЕ КАК ПРЕДИКТОР УЧЕБНОЙ МОТИВАЦИИ ИНОСТРАННЫХ СТУДЕНТОВ ${ }^{1}$
}

В статье рассматриваются результать эмпирического исследования мотивации учебной деятельности студентов из зарубежсных стран, влияние восприятия иностранными студентами собственного благополучия в иной сочиокультурной среде на мотивацио их учебной деятельности. Установлено, что восприятие собственного благополучия в инокультурной среде взаимосвязано с характеристиками учебной мотивации и имеет выраженную кросс-культурную специфику, которая должна быть учтена при работе с иностранныли студентами вуза.

Ключевые слова: мотивация учебной деятельности, сочиокультурная безопасность, благополучие, сочиокультурная среда, кросс-культурные особенности, иностранные студенты, регрессионньй анализ.

\section{Vladimir Solomonov \\ PERCEPTION OF OWN WELL-BEING IN THE IN-CULTURAL ENVIRONMENT AS A PREDICTOR OF TRAINING MOTIVATION OF FOREIGN STUDENTS}

The article examines the results of an empirical study of the motivation of students academic activity from foreign countries, the impact of foreign students' perception of their own well-being in a different sociocultural environment on the motivation of their educational activities. It is established that the perception of one's own well-being in an inocultural environment is interconnected with the characteristics of educational motivation and has a pronounced cross-cultural specifics that should be taken into account when dealing with foreign students at a university.

Key words: motivation of educational activity, socio-cultural security, well-being, sociocultural environment, cross-cultural characteristics, foreign students, regression analysis.

Bведение / Introduction. Современное университетское образование находится в настоящее время в своеобразной ситуации. С одной стороны, образовательные запросы обучающихся становятся более конкретными и целенаправленными, увеличивается интерес к образовательным программам различного формата, в том числе и в режиме online, повышается академическая мобильность студенческой молодежи. При этом в условиях обновления содержания почти всех профессиональных областей и требований работодателей педагоги-практики и исследователи образования отмечают изменение традиционной учебной мотивации студентов [2; 5 и др.].

Проблема учебной мотивации обучающихся является одной их центральных для отечественных педагогики и педагогической психологии. В работах Л. И. Божович было показано, что учебная мотивация характеризует личность учащегося. А. К. Маркова в русле рассмотрения учебной деятельности как полимотивированной исследовала структуру мотивации и иерархии мотивов. Учеными было показано, что к учебной деятельности (школьника) и учебно-профессиональной деятельности (студента) побуждают как направленность и мотивация обучающегося, так и условия протекания деятельности, включающие личностный вклад педагога, организацию учебного процесса, корпоративную культуру образовательной организации. Важное значение, что было подтверждено исследованиями, имеют социально-психологические отношения субъектов

Работа выполнена при финансовой поддержке РФФИ, проект № 18-013-00832 «Влияние аккультурационных установок на социокультурную безопасность студентов». 
образовательного процесса [3 и др.]. Как показано в работе Д. Л. Меламеда, «профиль учебно-профессиональной мотивации студентов связан с их статусом в неформальной структуре учебной группы, а также с особенностями объединяющей их учебной группы» [4, с. 13]. Для студентов, прибывших на обучение из другой страны, социально-психологические составляющие учебного процесса приобретают еще большее значение.

Особенности учебной мотивации в зависимости от реально существующих и воспринимаемых отношений в студенческой группе могут проявляться еще более остро при условии, что студент прибыл на обучение из-за рубежа, является представителем иной культуры [1; 7 и др.]. В этом случае к тревогам по поводу учебных достижений, отношений с однокурсниками и преподавателями по поводу статуса в группе добавляются переживания своего благополучия или неблагополучия в новой социокультурной среде.

Понятие социокультурного благополучия и социокультурной безопасности неразрывно связано с понятием социокультурной угрозы и, в свою очередь, с процессами аккультурации мигрантов, малочисленных этнических групп. В зарубежной науке более исследованными являются вопросы социокультурной безопасности для небольших, зачастую маргинализированных групп и этносов, на развитие и поддержание которых выделяются гранты и реализуются государственные программы. Такие исследования проводятся во многих странах. В качестве лидеров выступают исследования в США, где акцент делается преимущественно на реабилитацию лиц группы риска (М. Ангар, М. Райт, А. Мастен, Л. Терон, Л. Либенберг, Т. Спенсер, К. Пантер-Брик), в Австралии и Новой Зеландии, Канаде, где больше внимания уделяют восстановлению, поддержанию и развитию культуры коренных народов (В. Станнер, М. Бамблет, Дж. Харрисон, Л. Питер, Р. Франкланд, М. Гуда, Э. Прайдей, Э. Гаргет) [6]. В нашей стране исследования социокультурной безопасности и благополучия пока немногочисленны, поскольку проблема стала осмысливаться в научном сообществе относительно недавно, в постсоветский период [8].

Целью проведённого нами исследования стало изучение влияния восприятия иностранными студентами собственного благополучия в иной социокультурной среде на мотивацию их учебной деятельности. Гипотеза исследования основывалась на предположении о наличии связи между представлениями студентов о собственном благополучии в иной социокультурной среде и особенностями их мотивации к учебной деятельности.

Maтериалы и методы / Materials and methods. В эмпирическую выборку исследования вошли 158 студентов 1 курса Северо-Кавказского федерального университета (СКФУ) в возрасте от 18 до 25 лет, из них 66 человек - иногородние студенты из России и 92 студента из Средней Азии, арабских стран, Анголы и других стран Африки.

В процессе исследования данной проблемы использовались «Методика диагностики мотивации учебной деятельности личности в юношеском возрасте» [5], анкеты «Социокультурная безопасность» и «Оценка статуса студента в группе», разработанные сотрудниками Научно-образовательного центра психологического сопровождения личностно-профессионального развития Северо-Кавказского федерального университета.

«Методика диагностики мотивации учебной деятельности личности в юношеском возрасте» позволяет измерять силу учебных мотивов и оценивать иерархическую структуру мотивации учения студентов в вузе (МСБ). Она включает шкалы:

1) мотивы достижения цели (МДЦ), инициирующие учебную деятельность как инструмент для достижения личностно значимой цели. Являются наиболее продуктивными;

2) процессуальные мотивы (ПМ), предполагающие, что деятельность активизирована либо интересом к ней самой же, либо интересом к складывающейся в процессе учебы ситуации;

3) мотивы избегания (внешние) (МИ). Под влиянием мотивов данной группы студент включается в учебную деятельность, потому что хочет избежать чего-либо. (Ромусик Н. А., 2007). 
Анкета «Социокультурная безопасность» (МСБ) применялась с целью изучения восприятия иностранными студентами собственного благополучия в иной социокультурной среде. Концепция социокультурной безопасности, на основе которой разработана анкета, опирается на четыре ключевых, взаимосвязанных компонента: сохранность и развитие культуры, человеческое развитие, жизнестойкость субъекта, компетентные действия властей и самих представителей этнокультур. Вопросы анкеты распределены по шести шкалам: этническая идентичность и воссоздание продуктов культуры; картирование и реконструкция ресурсов; общая «жизнестойкость»; самоопределение; право голоса и субъектность; латеральное взаимодействие; культурно-компетентная окружающая среда.

Анкета «Оценка статуса студента в группе» позволяет конкретизировать представления о социокультурной безопасности и благополучии студента в широкой социальной общности оценками его благополучия в микросоциуме студенческой группы. В предложенной анкете представлен набор из 6 субшкал: успеваемость; материальное благополучие; «внешняя красота», готовность помочь; общительность; социальная активность. Первоначально респонденту предлагается проранжировать субшкалы по степени субъективной значимости для обретения студентом благоприятного статуса в группе (результат ранжирования отмечался символом «Р», ранг). Затем респондент должен оценить свой статус и благополучие в группе по этим шкалам в интервале от 1 до 5 («С», самооценка).

Обработка и анализ данных эмпирического исследования осуществлены при помощи математико-статистических методов с использованием пакета программ IBM SPSS Statistics 22 и MSExcel 2016. Был применен множественный регрессионный анализ методом пошагового исключения переменных в вычислениях.

Pезультаты и обсуждение / Results and discussion. В ходе математико-статистической обработки данных было построено 6 регрессионных моделей мотивации учебной деятельности у иностранных и иногородних студентов. В построенных нами регрессионных моделях F-отношение значимо на уровне 0,000 , соответственно, мы можем с уверенностью отвергнуть нулевую гипотезу (выявлены статистические закономерности).

Таблица 1

Регрессионная модель мотивации учебной деятельности студентов из России

\begin{tabular}{|l|c|c|c|c|}
\hline $\begin{array}{c}\text { Зависимая } \\
\text { переменная }\end{array}$ & $\boldsymbol{R}^{2}$ & $\boldsymbol{F}$ & $\begin{array}{c}\text { Независимая } \\
\text { переменная }\end{array}$ & $\boldsymbol{\beta}$ \\
\hline МДЦ & 0,062 & 4,242 & Р_Внешняя красота & $-0,249$ \\
\hline ПМ & 0,188 & 14,828 & Жизнестойкость & 0,434 \\
\hline
\end{tabular}

Примечание. Здесь и далее $\beta$ - стандартизированный коэффициент регрессии; $R^{2}$ - коэффиџиент детерминации; F-отночение зависимой и независимой переменной).

Рассматривая первую из регрессионных моделей мотивации студентов из России, необходимо отметить, что переменная «Внешняя красота» как значимый с точки зрения студентов фактор их благополучия в группе отрицательно коррелирует с учебной мотивацией достижения цели, и объясняет только 6,2\% дисперсии (табл. 1).

Вторая регрессионная модель (19\% дисперсии) показывает, что внешние «Процессуальные мотивы» поддерживаются за счет уровня жизнестойкости, готовности продуктивно справляться со стресс-факторами новой среды. 
Регрессионная модель мотивации учебной деятельности студентов из Анголы

\begin{tabular}{|l|c|c|l|c|}
\hline $\begin{array}{c}\text { Зависимая } \\
\text { переменная }\end{array}$ & $\boldsymbol{R}^{2}$ & $\boldsymbol{F}$ & $\begin{array}{r}\text { Независимая перемен- } \\
\text { ная }\end{array}$ & $\boldsymbol{\beta}$ \\
\hline МДЦ & 0,737 & \multirow{2}{*}{11,194} & Р_Общительность & $-0,597$ \\
\cline { 4 - 5 } & & С_Общительность & 0,472 \\
\hline
\end{tabular}

Регрессионная модель учебной мотивации студентов из Анголы (табл. 2) указывает на наличие двух предикторов: «Общительности» как значимого фактора достижения благополучия в группе и «Общительности» как выраженного личностного качества. С точки зрения респондентов, общительность может мешать достижению учебных целей, но в их конкретных случаях общительность помогает достигать благоприятного статуса в группе и поддерживает желание учиться.

Таблица 3

Регрессионная модель мотивации учебной деятельности студентов из стран Африки

\begin{tabular}{|c|c|c|c|c|}
\hline $\begin{array}{l}\text { Зависимая } \\
\text { переменная }\end{array}$ & $R^{2}$ & $F$ & Независимая переменная & $\beta$ \\
\hline МДЦ & 0,297 & 5,929 & C_Внешняя красота & 0,545 \\
\hline \multirow{6}{*}{ ПМ } & \multirow{6}{*}{0,959} & \multirow{6}{*}{54,266} & Латеральное взаимодействие & $-0,423$ \\
\hline & & & С_Готовность помочь & 0,556 \\
\hline & & & Культурно-компетентная среда & $-0,582$ \\
\hline & & & Жизнестойкость & 0,813 \\
\hline & & & Этническая идентичность & $-0,538$ \\
\hline & & & С_Общительность & 0,233 \\
\hline
\end{tabular}

Для учебной мотивации студентов из стран Африки созданы две регрессионные модели (табл. 3). Согласно первой модели, предиктором «Мотивов достижения цели» (МДЦ) при $30 \%$ вариаций дисперсии выступает фактор «Внешняя красота». Другими словами, успех в обучении молодые люди связывают с собственной привлекательностью, полагаются на внешнюю атрибутику и другие несущественные условия.

Вторая модель с зависимой переменной «Процессуальная мотивация» (ПМ) объясняет $54 \%$ дисперсии и имеет шесть независимых переменных, что означает разнообразие и разнонаправленность предикторов процессуальной мотивации. Положительное значение для поддержания процессуальной мотивации африканских студентов имеют факторы, характеризующие личностные свойства: «Жизнестойкость», «Готовность помочь» и «Общительность». Снижают процессуальную мотивацию учебной деятельности респондентов стремление сохранить собственную этническую идентичность и условия, в которых протекает учебная деятельность: недостаточная межкультурная компетентность представителей принимающей стороны, опыт негативных взаимодействий между студентами.

Таблица 4

Регрессионная модель мотивации учебной деятельности студентов из Средней Азии

\begin{tabular}{|l|c|c|l|c|}
\hline $\begin{array}{c}\text { Зависимая } \\
\text { переменная }\end{array}$ & $\boldsymbol{R}^{2}$ & $\boldsymbol{F}$ & \multicolumn{1}{|c|}{ Независимая переменная } & $\boldsymbol{\beta}$ \\
\hline \multirow{2}{*}{ МДЦ } & 0,669 & \multirow{2}{*}{11,461} & Латеральное взаимодействие & $-0,598$ \\
\cline { 4 - 5 } & & Ресурсы & $-0,326$ \\
\hline
\end{tabular}




\begin{tabular}{|c|c|c|c|c|}
\hline $\begin{array}{l}\text { Зависимая } \\
\text { переменная }\end{array}$ & $R^{2}$ & $F$ & Независимая переменная & $\beta$ \\
\hline \multirow{4}{*}{ МДЦ } & \multirow{4}{*}{0,669} & \multirow{4}{*}{11,461} & Р_Успеваемость & 0,487 \\
\hline & & & P_Внешняя красота & 0,376 \\
\hline & & & P_Материальное благополучие & 0,490 \\
\hline & & & Культурно-компетентная среда & $-0,412$ \\
\hline \multirow{4}{*}{ МИ } & \multirow{4}{*}{0,685} & \multirow{4}{*}{8,702} & Жизнестойкость & $-0,614$ \\
\hline & & & Р_Успеваемость & 0,244 \\
\hline & & & R_Готовность помочь & $-0,492$ \\
\hline & & & R_Внешняя красота & $-0,349$ \\
\hline
\end{tabular}

Так же как и для студентов из Африки, для студентов из Средней Азии созданы две модели с зависимой переменой «Мотивы достижения цели» (МДЦ) и «Мотивы избегания» (МИ), которые объясняют 67 \% и 25 \% вариации зависимой величины, соответственно (табл. 4).

Предикторы зависимой переменной «Мотивы достижения цели» (МДЦ) показывают, что студенты из азиатских республик серьезное значение придают материальной стороне дела. Их стремление к цели поддерживается высокими оценками «Успеваемости», «Внешней красоты» и «Материального благополучия» как инструментов завоевания высокого статуса в группе. Мотивация достижения цели снижается в условиях низкой межкультурной компетентности представителей принимающей стороны, значительных отличий принимающей культуры и негативного опыта взаимодействия. Эти данные согласуются с полученными нами ранее $[1,7]$.

Согласно второй модели с независимой переменной «Мотивы избегания» (МИ), «Успеваемость» служит для молодых людей средством избегания каких-то неприятностей. Мотивация избегания у них повышается, если студенты невысоко оценивают собственную жизнестойкость, не считают «Внешнюю красоту» и «Готовность помочь» значимыми для достижения благоприятного статуса в группе.

Таблица 5

Регрессионная модель мотивации учебной деятельности студентов из арабских стран

\begin{tabular}{|l|c|c|l|c|}
\hline $\begin{array}{c}\text { Зависимая } \\
\text { переменная }\end{array}$ & $\boldsymbol{R}^{2}$ & $\boldsymbol{F}$ & \multicolumn{1}{|c|}{ Независимая переменная } & $\boldsymbol{\beta}$ \\
\hline ПМ & 0,975 & \multirow{2}{*}{24,812} & Субъектность & 0,948 \\
\cline { 4 - 5 } & & С_Социальная активность & $-0,162$ \\
\hline
\end{tabular}

У студентов из арабских стран значимые корреляции между мотивацией учебной деятельности и оценками собственного благополучия в инокультурной среде проявились по шкале «Процессуальные мотивы» (ПМ), предполагающей, что деятельность активизирована интересом к складывающейся в процессе учебы ситуации (табл. 5). Предикторами данной модели являются «Субъективность» и проявляемая, по их мнению, «Социальная активность».

Заключение / Conclusion. Проведенное исследование позволило подтвердить выдвинутую гипотезу и выявить влияние представлений о собственном благополучии в новой социокультурной среде на характер мотивации к учебной деятельности; это влияние имеет выраженные кросс-культурные особенности.

Выбранные в качестве контрольной группы студенты из России априори лучше адаптированы к обучению в другом населенном пункте родной страны, чем иностранцы, хотя все первокурсники, безусловно, попадают в новую социокультурную среду в начале вузовского обучения. Восприятие молодыми россиянами своего благополучия в студенческой среде способно оказать 
влияние на их мотивацию достижения цели в учебной деятельности. По их мнению, внешняя привлекательность, способность произвести хорошее впечатление на однокурсников не имеют отношения к учебной деятельности. Негативный аспект такой позиции может проявляться в недооценке качества оформления своих работ, невнимании к внешнему виду своему и продуктов своего труда. Процессуальная мотивация учебной деятельности поддерживается за счет высокой готовности продуктивно справляться со стрессовыми ситуациями, что обозначается термином «жизнестойкость» (Леонтьев Д. А., 2004). Можно сделать вывод, что молодые россияне в своей массе адекватно настроены на преодоление трудностей в учебе за счет интеллектуальных усилий и высокой адаптивности.

Для студентов из Анголы восприятие своего благополучия имеет значение для динамики мотивации достижения целей учебной деятельности, как и для россиян. Эти мотивы поддерживаются на высоком уровне, за счет того, что молодые ангольцы, по их мнению, проявляют общительность, устанавливают контакты, получают возможность воспользоваться помощью. При этом они невысоко оценивают общительность как инструмент достижения благоприятного статуса в группе, что может ограничивать их инициативу во взаимодействии с представителями иной культуры. Ранее проведенные нами исследования показывают, что студенты из Анголы держатся более обособленной группой, чем их ровесники из других стран. Кроме того, в СКФУ количество ангольских студентов достаточно, чтобы они могли взаимодействовать преимущественно друг с другом.

У студентов из других африканских стран, за исключением ангольцев, выражены мотивы достижения целей в учебной деятельности и процессуальные мотивы. Их учебная мотивация в значительной степени зависит от восприятия условий осуществления образовательного процесса. Студенты из Африки озабочены тем, чтобы производить положительное внешнее впечатление, считают его фактором учебных достижений. Процессуальная мотивация будет повышаться, если они попадают в условия гибко организованного учебного процесса, получают возможность продемонстрировать свою общительность и готовность помочь другим. Это дает молодым африканцам чувство сохранности собственной идентичности. В свою очередь, студенты ждут помощи и положительного интереса к их культуре со стороны других обучающихся и сотрудников вуза.

Студенты из республик Средней Азии оказались единственной группой, для кого учебная деятельность подпитывается и мотивами достижения целей, и мотивами избегания, что достаточно противоречиво. Мотивы достижения целей активизируются за счет того значения, которое представители среднеазиатских стран придают успеваемости, внешней привлекательности и материальному благополучию. Интересно, что ни по одному из выделенных критериев респонденты себя высоко не оценили, тем самым подразумевая, что не воспринимают свое положение в пространстве российского вуза как благополучное. Ситуация усугубляется тем, что студенты в большинстве своем пережили опыт с неблагоприятного взаимодействия, испытывают сложности в поддержании привычного образа жизни, недостаток понимания и интереса к своим культурным особенностям.

Мотивы избегания, в свою очередь, служат побуждением к поддержанию успеваемости студентов на должном уровне. Они тем более интенсивны, чем ниже стрессоустойчивость конкретных респондентов и их способность продуктивно справляться с трудностями. Молодые люди из Средней Азии оценивают как важное условие достижения благоприятного статуса в группе готовность помогать и внешнюю привлекательность. При этом ни по одному из критериев, значимых, по их мнению, для достижения благополучия в инокультурной среде, они себя не оценили высоко.

Арабские студенты, в отличие от всех остальных респондентов, в наибольшей степени сосредоточены на событиях, которые происходят вокруг учебного процесса, а не «внутри» него. Восприятие своего статуса среди других обучающихся может повлиять преимущественно на их процессуальную мотивацию, усиливая или ослабляя интерес к окружающим событиям. Они на- 
строены наиболее независимо, высоко оценивают проявляемую социальную активность, готовы влиять на организацию учебного процесса. В противном случае, их интерес к учебной деятельности снижается.

Проведенное исследование показало, что субъъективное восприятие своего благополучия в новой социокультурной среде сказывается на структуре мотивации учебной деятельности иностранных студентов и выраженности отдельных ее составляющих вполне определенным образом. В образовательном процессе это не только означает необходимость индивидуального подхода к обучающемуся, но и требует учета его социокультурных особенностей.

\section{ЛИТЕРАТУРА И ИНТЕРНЕТ-РЕСУРСЫ}

1. Банщикова Т. Н., Соломонов В. А., Фомина Е. А. Предикторы учебной мотивации современных студентов // Сборник материалов III Международной научно-практической конференции «Фундаментальные научные исследования: теоретические и практические аспекты» 29-30 января 2017 г., г. Кемерово. Кемерово, 2017. С. 304-307.

2. Гордеева Т. О. Базовые типы мотивации деятельности: потребностная модель // Вестник Московского университета. Серия 14. Психология. 2014. № 3. С. 63-78. URL: http://msupsyj.ru/articles/detail. php?article=5179 (дата обращения 14.09.2018).

3. Кондратьев Ю. М. Особенности отношений межличностной значимости и взаимовосприятия в студенческих учебных группах // Социальная психология и общество. 2012. № 2. С. 62-79. URL: http:// psyjournals.ru/files/51627/social_psy_2012_n2_Kondratyev.pdf. (дата обращения 12.09.2018).

4. Меламед Д. Л. Социально-психологические особенности учебно-профессиональной мотивации студентов [Электронный ресурс] // Психологическая наука и образование. 2011. № 2. C. 1-14. URL: http://psyjournals.ru/files/41673/psyedu_ru_2011_2_Melamed.pdf. (дата обращения 14.09.2018).

5. Ромусик Н. А. Методика диагностики мотивации учебной деятельности личности в юношеском возрасте // Психологический журнал. 2007. № 1. С. 43-51.

6. Соколовский М. Л. Концепт «социокультурная безопасность» и его практическое применение // Личностный ресурс субъекта труда в изменяющейся России: материалы V Международной научно-практической конференции 5-7 октяб̆ря 2018 г., Пятигорск. Ч. ІІ / Симпозиум «Труд и его суб́ъект в изменяющейся России». Невинномысск, 2018. С. 234-242. doi:10.30888/978-5-6041451-4-2.2.39.

7. Соломонов В. А., Фомина Е. А. Особенности саморегуляции иностранных студентов в новой социокультурной среде // Личностный ресурс субъекта труда в изменяющейся России: материалы V Международной научно-практической конференции 5-7 октября 2018 г., Пятигорск Ч. I: Симпозиум «Субъект и личность в психологии саморегуляции». Невинномысск, 2018. С. 193-198. doi: 10.30888/978-5-6041451-4-2.1.27.

8. Шамионов Р. М. Критерии суббъективного благополучия личности // Известия Саратовского университета. Новая серия. Серия Акмеология образования. Психология развития. 2015. Т. 4. Вып. 3. С. 213-217.

\section{REFERENCES AND INTERNET RESOURCES}

1. Banshchikova T. N., Solomonov V. A., Fomina Ye. A. Prediktory uchebnoy motivatsii sovremennykh studentov (Predictors of the motivation of modern students) // Sbornik materialov III Mezhdunarodnoy nauchno-prakticheskoy konferentsii «Fundamental'nyye nauchnyye issledovaniya: teoreticheskiye i prakticheskiye aspekty» 29-30 yanvarya 2017 g., Kemerovo. Kemerovo, 2017. P. $304-307$.

2. Gordeyeva T. O. Bazovyye tipy motivatsii deyatel'nosti: potrebnostnaya model' (Basic types of activity motivation: the need model) // Vestnik Moskovskogo universiteta. Seriya 14. Psikhologiya. 2014. No 3. P. 63-78. URL: http://msupsyj.ru/articles/detail.php?article=5179 (data obrashcheniya 14.09.2018).

3. Kondrat'yev YU. M. Osobennosti otnosheniy mezhlichnostnoy znachimosti i vzaimovospriyatiya v studencheskikh uchebnykh gruppakh (Peculiarities of interpersonal importance and mutual perception in student groups) // Sotsial'naya psikhologiya i obshchestvo, 2012. No 2. P. 62-79. URL: http://psyjournals. ru/files/51627/social_psy_2012_n2_Kondratyev.pdf. (data obrashcheniya 12.09.2018). 
4. Melamed D. L. Sotsial'no-psikhologicheskiye osobennosti uchebno-professional'noy motivatsii studentov [Elektronnyy resurs] (Socio-psychological characteristics of the educational and professional motivation of students) // Psikhologicheskaya nauka i obrazovaniye. 2011. No 2. P. 1-14. URL: http://psyjournals.ru/ files/41673/psyedu_ru_2011_2_Melamed.pdf. (data obrashcheniya 14.09.2018).

5. Romusik N. A. Metodika diagnostiki motivacii uchebnoj deyatel'nosti lichnosti v yunosheskom vozraste (The method of diagnosing the motivation of the educational activity of an individual in adolescence) // Psihologicheskij zhurnal. 2007. No 1. P. 43-51.

6. Sokolovskiy M. L. Kontseptsiya «sotsiokul'turnaya bezopasnost'» i yego prakticheskoye primeneniye (The concept of «sociocultural security» and its practical application) // Materialy V Mezhdunarodnoy nauchnoprakticheskoy konferentsii 5-7 oktyabrya 2018 g., g. Pyatigorsk. CH. II: Simpozium «Trud i yego sub"yekt v izmenyayushcheysya Rossii». Nevinnomyssk, 2018. P. 234-242. doi: 10.30888 / 978-5-6041451-4-2.2.39

7. Solomonov V. A., Fomina Ye. A. Osobennosti samoregulyatsii inostrannykh studentov $v$ novoy sotsiokul'turnoy srede (Features of self-regulation of foreign students in a new socio-cultural environment) // Materialy V Mezhdunarodnoy nauchno-prakticheskoy konferentsii 5-7 oktyabrya 2018 g., g. Pyatigorsk. CH. I: Simpozium «Sub"yekt i lichnost' v psikhologii samoregulyatsii». Nevinnomyssk, 2018, P. 193-198. doi: 10.30888 / 978-5-6041451-4-2.1.27.

8. Shamionov R. M. Kriterii sub"yektivnogo blagopoluchiya lichnosti (Criteria of subjective well-being of the individual) // Izvestiya Saratovskogo universiteta. Novaya seriya. Seriya Akmeologiya obrazovaniya. Psikhologiya razvitiya. 2015. V. 4. I. 3. P. 213-217.

\section{СВЕДЕНИЯ ОБ АВТОРЕ}

Соломонов Владимир Александрович, кандидат психологических наук, доцент, доцент кафедры педагогики и психологии профессионального образования, Институт образования и социальных наук, Северо-Кавказский федеральный университет. E-mail: vlads67@mail.ru

\section{INFORMATION ABOUT AUTHOR}

Solomonov Vladimir, Candidate of Psychological Sciences, Associate Professor, Associate Professor of Pedagogy and Psychology of Professional Education, Institute of Education and Social Sciences, North Caucasus Federal University. E-mail: vlads67@mail.ru 